\title{
The true malignancy risk of Bosniak III cystic renal lesions: Active surveillance or surgical resection?
}

Cameron Jonathan Lam ${ }^{1}$; Anil Kapoor ${ }^{2}$

${ }^{1}$ Michael G. DeGroote School of Medicine; ${ }^{2}$ Department of Surgery, Division of Urology, McMaster University; Hamilton, ON, Canada

Cite as: Can Urol Assoc J 2018 Feb. 23; Epub ahead of print. http://dx.doi.org/10.5489/cuaj.4960

Published online February 23, 2018

$* * *$

Abstract

Introduction: We sought to evaluate the pathological results of renal masses in comparison with Bosniak III renal cystic lesions to determine the actual malignancy risk.

Methods: A retrospective review of Bosniak III renal lesions identified by computed tomography (CT) or magnetic resonance imaging (MRI) were collected from our patients between August 1, 2013 and December 31, 2015 who underwent surgical excision. TNM stage, histology, Fuhrman grade, and maximum lesion size data was collected. Lesion size relationship with prevalence of malignancy was completed by two-tailed t-test, using the homogeneity hypothesis between malignant and benign groups.

Results: Fifteen of 25(60\%) of Bosniak III lesions were determined to be malignant. All malignant lesions were classified as either Fuhrman grade 1 or 2 with no evidence of progression to Bosniak IV. Average size of malignant lesions was smaller than those of benign pathology $(3.52 \pm 1.99 \mathrm{~cm}$ vs. $5.66 \pm 2.53 \mathrm{~cm}$; $\mathrm{p}=0.041)$. Smaller lesions (size $<4 \mathrm{~cm}$ ) were more likely to be malignant than lesions of a larger size $(\mathrm{p}=0.047)$.

Conclusions: The malignancy risk of Bosniak III renal lesions was $60 \%$ in our study. All Bosniak III lesions were of low Fuhrman grade with no evidence of progression. No patient in this study developed metastatic disease within the three-year followup period. Smaller $(<4 \mathrm{~cm})$ Bosniak III cysts were more likely to be malignant and lesion size should be taken into consideration when considering management of complex cysts. Active surveillance may be a reasonable option for Bosniak III cystic lesions, regardless of overall size, based upon their universal low grade and no patient developing metastatic disease. 


\section{Introduction}

The Bosniak renal cyst classification system is a well-established method that uses contrast enhanced computed tomographic (CT) findings to categorized cystic renal masses into groups with associated risk of malignancy. ${ }^{1,2}$ Briefly, this system separates simple and mildly complex cystic renal lesions as Bosniak categories I and II, respectively, which do not require further follow-up. Since its original description an additional category of IIF has been added to identify increased abnormal findings with recommendation for regular follow-up. ${ }^{3,4}$ Bosniak category IV is considered to have malignancy risk greater than $80 \%$ and surgical excision is recommended in able bodied patients. Bosniak category III cystic masses are of indeterminate origin, thought to have a malignant risk of 40-60\%, and surgical excision is recommended. ${ }^{1,5,6}$

Though the malignant potential of Bosniak III cysts are stated to be approximately 40-60\% several studies have demonstrated different rates ranging from $41 \%{ }^{7}$ to $84 \%{ }^{8}$ correlating with final pathology. Most studies did not require a single observer interpretation of radiologic findings as it has been shown that a good degree of interobserver agreement exists in assessment of complex renal cysts. ${ }^{9}$

Though the original Bosniak classification was based on CT findings though many institutions use non-radiation modalities such as magnetic resonance imaging (MRI) for categorizing complex renal cysts. Studies have shown that MRI ${ }^{10,11}$ are equally useful as CT for characterization of cystic masses.

Here, we performed a retrospective review of Bosniak III renal cystic lesions classified radiographically by $\mathrm{CT}$ and MRI at one academic care centre with evaluation of pathological diagnosis and lesions to determine the actual malignancy risk.

\section{Methods}

Institutional board review and informed consent was obtained for this study.

We performed a retrospective review of Bosniak III lesions at our academic institution to evaluate pathologic diagnosis and radiographic findings. The hospital information system (Horizon(WP) Provider Portal, McKesson, San Francisco, CA) and radiology information system (PACS Centricity Enterprise, GE Healthcare, Chicago, IL) was searched from August 1, 2013 to December 31, 2015 for adult patients (>18 years of age) in our clinic with Bosniak III lesions. Inclusion criteria consisted of patients who had one or more Bosniak III lesions characterized by CT or MRI and underwent surgical excision. This was correlated to final pathology. Fuhrman grade 1 and 2 were considered a less aggressive malignancy while Fuhrman grade 3 and 4 were classified as aggressive subtypes.

Data from 25 patients were reviewed for pathological malignancy in the final analysis. These cases were not controlled for single radiologist interpretation over the time period. These cases' most recent radiographic findings on CT or MRI prior to surgical excision were all classified as Bosniak III cystic renal lesions. Nephron sparing surgeries were performed in eleven cases and radical nephrectomies were performed in the remaining fourteen cases. 
Multidetector CT scans were performed according to standard protocol covering the abdomen while the patient was placed in the supine position. Pathology specimen reports were reviewed and categorized as benign or malignant and used the 2010 AJCC TNM staging classification for kidney cancer. $^{12}$

\section{Statistical analysis}

Prediction of lesion size in relation to prevalence of malignancy was done by means of a twotailed t-test using the homogeneity hypothesis between pathology results between malignant and benign groups. A statistically significant difference by which the two groups would be considered different was taken to be indicated by a P-value of less than 0.05 . A hypothesis test for two population proportions was used to determine was done with $1 \mathrm{~cm}$ intervals to compare proportions of benign versus malignant lesions at different lesion sizes using Fischer's exact test.

\section{Results}

Twenty five patients with Bosniak III lesions were included in this study with an average age of $58.6 \pm 12.2$ years with a total of 9 males and 16 females. There were 15 lesions $(60 \%)$ on the right side and $10(40 \%)$ on the left side. Mean lesion size of all cases was $4.41 \pm 2.42 \mathrm{~cm}$ (range $1.0-12.0 \mathrm{~cm})$.

Of the 25 cases, 15 were malignant (60\%) and 10 were benign complex cysts (40\%). Surgical pathology of the malignant lesions revealed 2/15 (13\%) were papillary RCC while the remaining 13/15 (87\%) were clear cell RCC. Of the malignant lesions 5/15 (33\%) were Fuhrman G2, 9/15 (60\%) Fuhrman G1, while Fuhrman grade was not available for 1 lesion.

According to TNM staging 9/15 (60\%) malignant lesions were pT1a ( $<4 \mathrm{~cm}$ in diameter, limited to the kidney), 4/15 (27\%) were pT1b (4-7 cm in diameter, limited to the kidney), and 1/15 (7\%) was pT2a (7-10 cm in diameter, limited to the kidney). One lesion was suspicious for RCC and was sent for consultation which confirmed unilocular RCC though the tumor cells were well under $1 \%$ of the mass and that staging the lesion as pT2 based on its $12 \mathrm{~cm}$ size would not be appropriate and was staged as pTX. For this reason, this specimen was not included in the size comparisons of lesions. Radiological and pathological findings are summarized below in Table 3.

Comparison of lesion size as a predictor of malignancy on pathological analysis displayed statistical difference of average lesion size and prevalence of malignancy $(\mathrm{p}=0.041)$ (Table 1, Figure 1).

Smaller lesions (size $<4 \mathrm{~cm}$ ) were shown to be more likely to be malignant than lesions of a larger size (Fischer's exact test: $\mathrm{p}=0.047$ ) based on a proportional comparison of maximum lesion dimension shown in Table 2. A binary regression of the data revealed a trend identifying a decreasing probability of malignancy with larger lesion size (decreased likelihood of 1.554 for every $1.0 \mathrm{~cm}$ increase in size) on average though further investigation with increasing sample sizes may provide clearer data (pseudo $\mathrm{R}^{2}=15.44 \%$ ) (Figure 2 ). 


\section{Discussion}

This study demonstrated probability of malignancy of $60 \%$ in renal lesions classified as Bosniak III by CT or MRI. Several studies have demonstrated various different malignancy rates of

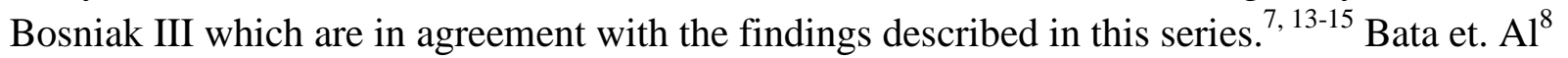
has recently shown much higher probability of malignancy (84\%) in Bosniak III lesions in their series, though the sample size was 19 patients.

While both papillary RCC and clear cell RCC were present in this series, the Bosniak III lesions were predominantly clear cell RCC, the most common type of RCC. ${ }^{16}$ This does reinforce the principle that cystic lesions which are malignant do not necessarily equate to clear cell RCC. It remains an important finding here as various malignant neoplasms exist which can potentially alter management options. ${ }^{17,18}$

The short-term results of this series showed that $100 \%$ of all malignancies were Fuhrman G1/2 and no development of metastatic disease during the 3 year period of follow-up in this study. Therefore, active surveillance may be an option for Bosniak III cystic masses regardless of size as all pathologies were low grade with low metastatic potential.

Lesion size does appear to play a statistically significant $(p=0.041)$ role in the determination of malignancy of Bosniak III classified renal masses of this series. The results of this study identified that a smaller lesion size tended to be associated with malignancy though further investigation with larger sample sizes may be required to further reinforce this finding. Han et al. ${ }^{15}$ also reported that lesion size should be taken into account for formulation of treatment, though they identified that lesions smaller than $2 \mathrm{~cm}$ are likely benign. The previous study only reported on lesions less than or greater than $2 \mathrm{~cm}$ and included Bosniak II-IV lesions, but did not comment on the spectrum of lesion size. Proportional comparison of the data in our study used several cut-off values for lesion size, at $1.0 \mathrm{~cm}$ intervals, which could identify benign from malignant tumours. Significance was identified at the $4 \mathrm{~cm}$ boundary.

These results showing that smaller Bosniak III lesions had higher risk of being malignant was somewhat unexpected. Though a direct relationship between size and malignancy exists for solid renal masses, this is less well understood in cystic lesions. This relationship between the larger cystic lesion sizes may be in part due to relatively increased functional fluid secretion tissue versus that of malignant lesions which secrete less fluid. Though we attempted to compare the proportion of pre-operative images which contained solid components to lesion size no significance was identified within our sample and may be an area for further study.

Goenka et al. ${ }^{14}$ developed a clinical prediction model for malignancy risk of Bosniak III renal lesions concluding that smaller lesion size confers higher risk of malignancy with a large sample size of 107 in agreement with this data.

There were some limitations of this study including the retrospective design. Radiologists who were involved in interpretation of CT or MRI were not standardized and though there is evidence that interobserver effect is minimal in complex renal cysts ${ }^{9}$ application of the Bosniak classification system it remains subjective system. Finally, the overall sample size of this series 
was relatively small and a study involving a larger number of patients may be helpful in validating the overall malignancy risk and prediction power of lesion size in Bosniak III cysts.

\section{Conclusion}

The malignancy risk of Bosniak III renal cysts is $60 \%$ in our study. The data collected from this series suggests that the smaller Bosniak III cysts carry higher risk of malignant final pathology though larger studies may be required in the future to clarify the data. Lesions $<4 \mathrm{~cm}$ showed a significant increase in the likelihood of malignancy; decisions for surveillance versus surgical excision of complex renal cysts which may represent RCC should consider lesion size as a primary factor. There was no evidence of progression from Bosniak III to Bosniak IV of patients in this study or development of locally advanced or metastatic disease within the 3 year follow up period. Finally, 100\% of all malignancies were classified as a less aggressive grade (Fuhrman grade $<$ G2). This data can be used to counsel patients with regards to the option of active surveillance for Bosniak III masses regardless of size as all pathologies were low grade and no patient developed metastatic disease. 


\section{True malignancy risk of Bosniak III cystic renal lesions}

\section{References}

1. Bosniak, M.A., The current radiological approach to renal cysts. 1986;158:1-10.

2. Bosniak, M.A., The Bosniak renal cyst classification: 25 years later. 2012;262:781-5.

3. Bosniak, M.A., The Use of the Bosniak Classification System for Renal Cysts and Cystic Tumors. 1997;157:1852-53.

4. Bosniak, M.A., Diagnosis and management of patients with complicated cystic lesions of the kidney. 1997;169:819-21.

5. Whelan, T.F., Guidelines on the management of renal cyst disease. 2010;4:98-9.

6. Israel, G.M. and M.A. Bosniak, An update of the Bosniak renal cyst classification system. 2005;66:484-8.

7. Cloix, P., X. Martin, C. Pangaud, et al., Surgical management of complex renal cysts: a series of 32 cases. 1996;156:28-30.

8. Bata, P., A.D. Tarnoki, D.L. Tarnoki, et al., Bosniak category III cysts are more likely to be malignant than we expected in the era of multidetector computed tomography technology. 2014;19:634-8.

9. El-Mokadem, I., M. Budak, S. Pillai, et al., Progression, interobserver agreement, and malignancy rate in complex renal cysts ( >/= Bosniak category IIF). 2014;32:24 e21-7.

10. Balci, N.C., R.C. Semelka, R.H. Patt, et al., Complex renal cysts: findings on MR imaging. 1999;172:1495-500.

11. Israel, G.M., N. Hindman, and M.A. Bosniak, Evaluation of cystic renal masses: comparison of CT and MR imaging by using the Bosniak classification system. 2004;231:365-71.

12. Edge, S.B., AJCC cancer staging manual. 7th ed. / ed, ed. S.B. Edge and C. American Joint Committee on. 2010, New York ; London: Springer.

13. Smith, A.D., E.M. Remer, K.L. Cox, et al., Bosniak category IIF and III cystic renal lesions: outcomes and associations. 2012;262:152-60.

14. Goenka, A.H., E.M. Remer, A.D. Smith, et al., Development of a clinical prediction model for assessment of malignancy risk in Bosniak III renal lesions. 2013;82:630-5.

15. Han, H.H., K.H. Choi, Y.T. Oh, et al., Differential diagnosis of complex renal cysts based on lesion size along with the Bosniak renal cyst classification. 2012;53:729-33.

16. Storkel, S. and E. van den Berg, Morphological classification of renal cancer. 1995;13:153-8.

17. Vera-Badillo, F.E., A.J. Templeton, I. Duran, et al., Systemic therapy for non-clear cell renal cell carcinomas: a systematic review and meta-analysis. 2015;67:740-9.

18. Ravaud, A., S. Oudard, M. De Fromont, et al., First-line treatment with sunitinib for type 1 and type 2 locally advanced or metastatic papillary renal cell carcinoma: a phase II study (SUPAP) by the French Genitourinary Group (GETUG)dagger. 2015;26:1123-8. 
Figures and Tables

Fig. 1. Boxplot of lesion size vs. malignancy in Bosniak III renal masses. *Indicates statistical outliers. Outliers were not included in lesion size calculations due to inability to classify histologically by TNM stage

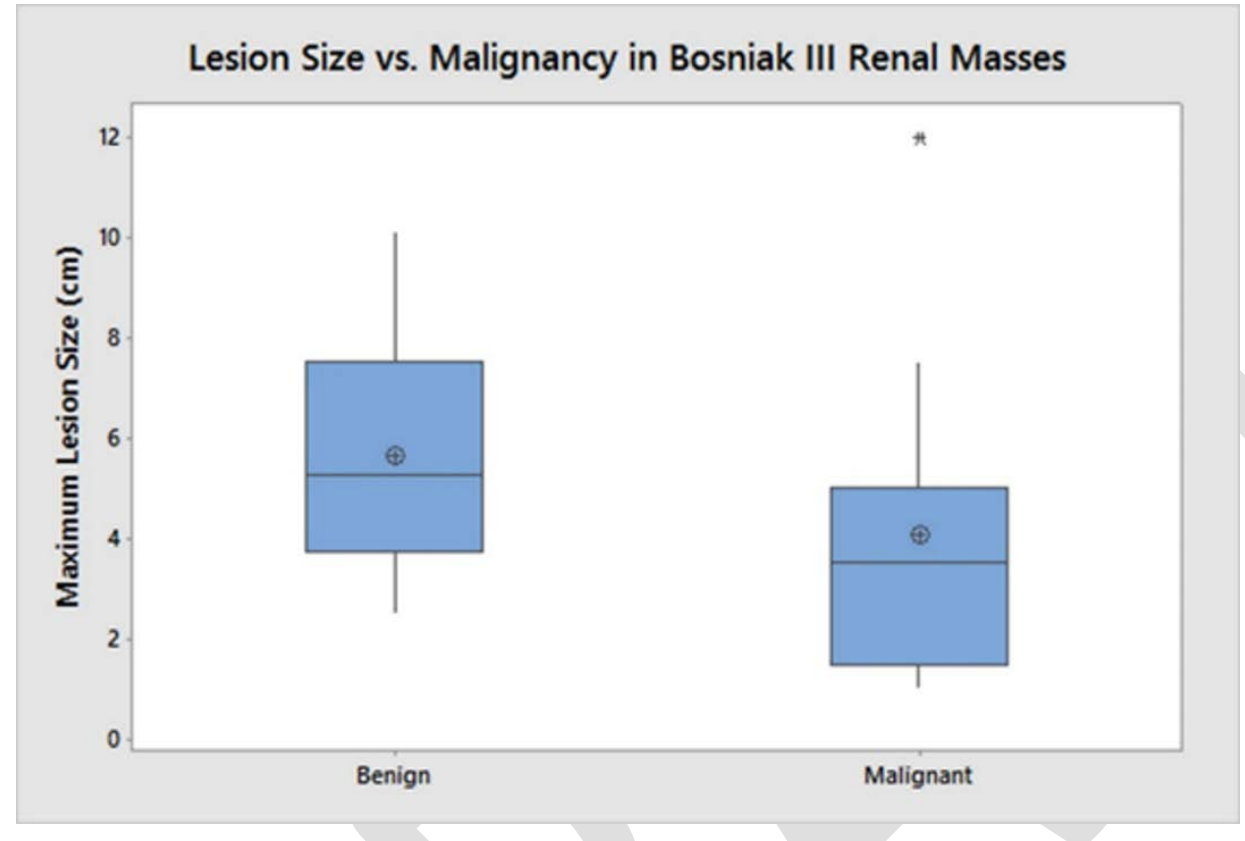

Fig. 2. Fitted line plot for probability of malignancy based on maximum lesion dimension.

Binary Fitted Line Plot for Risk of Malignancy vs Maximum Dimension

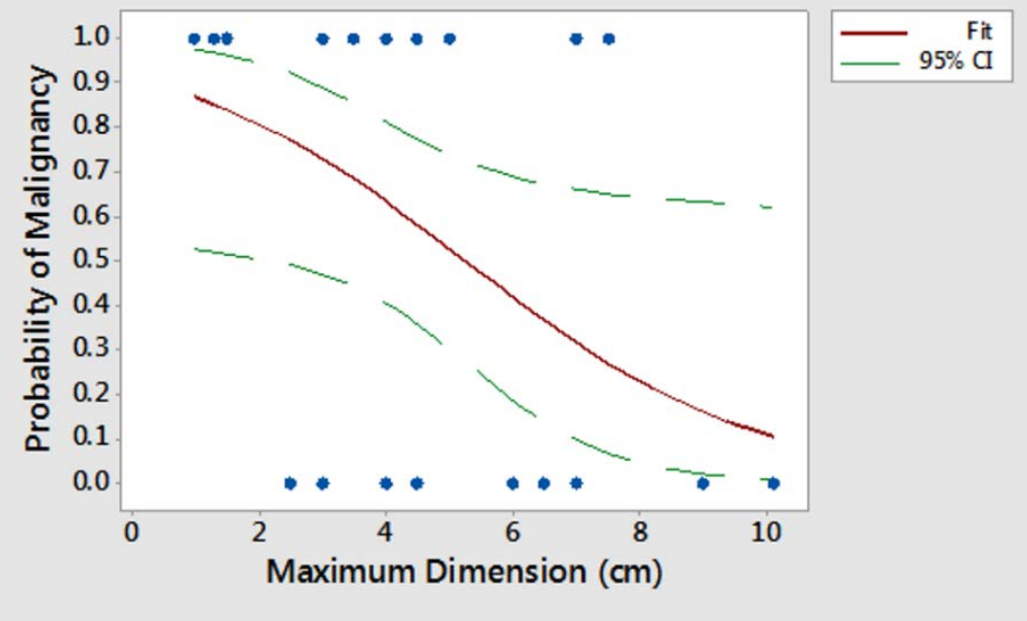




\begin{tabular}{|l|c|c|}
\hline \multicolumn{3}{|l|}{ Table 1. Average lesion size } \\
\hline & Sample size & Mean size (cm) \\
\hline Benign & 10 & $5.66 \pm 2.53$ \\
\hline Malignant & 14 & $3.52 \pm 1.99$ \\
\hline
\end{tabular}

Table 2. Proportional comparison of lesion size and malignancy

Number of malignancies/total cases (\%)

\begin{tabular}{|c|c|}
\hline$<4 \mathrm{~cm}$ & $\geq 4 \mathrm{~cm}$ \\
\hline $81.82 \%$ & $38.46 \%$ \\
\hline
\end{tabular}




\begin{tabular}{|c|c|c|c|c|c|}
\hline $\begin{array}{l}\text { Patient } \\
\#\end{array}$ & Gender & Age (at surgery) & $\begin{array}{l}\text { Classification } \\
\text { (on CT/MRI) }\end{array}$ & $\begin{array}{c}\text { Pathology/ } \\
\text { Fuhrman grade }\end{array}$ & $\begin{array}{l}\text { Maximum mass } \\
\text { dimension }(\mathrm{cm})\end{array}$ \\
\hline 1 & F & 66 & Bosniak III (CT) & $\begin{array}{c}\text { pT2a, pNX } \\
\text { Clear cell RCC } \\
\text { G2 }\end{array}$ & 7.50 \\
\hline 2 & $\mathrm{~F}$ & 75 & Bosniak III (CT) & $\begin{array}{c}\text { pT1b, pNX } \\
\text { Clear cell RCC } \\
\text { G1 }\end{array}$ & 4.50 \\
\hline 3 & M & 66 & Bosniak III (CT) & $\begin{array}{c}\text { pT1b, pNX } \\
\text { Clear cell RCC } \\
\text { G1 }\end{array}$ & 3.00 \\
\hline 4 & $\mathrm{~F}$ & 41 & Bosniak III (MRI) & $\begin{array}{c}\text { pT1b, pNX } \\
\text { Clear cell RCC } \\
\text { G1 }\end{array}$ & 7.00 \\
\hline 5 & $\mathrm{~F}$ & 80 & Bosniak III (MRI) & $\begin{array}{c}\text { pT1b, N0 } \\
\text { Papillary RCC }\end{array}$ & 5.00 \\
\hline 6 & F & 37 & $\begin{array}{l}\text { Bosniak III } \\
\text { (MRI/CT) }\end{array}$ & $\begin{array}{c}\text { pT1a, pNX } \\
\text { Clear cell RCC } \\
\text { G2 }\end{array}$ & 3.50 \\
\hline 7 & $\mathrm{M}$ & 66 & Bosniak III (CT) & $\begin{array}{c}\text { pT1a, pNX } \\
\text { Clear cell RCC } \\
\text { G1 }\end{array}$ & 3.50 \\
\hline 8 & $\mathrm{~F}$ & 60 & Bosniak III (MRI) & $\begin{array}{c}\text { pT1a, pNX } \\
\text { Clear cell RCC } \\
\text { G1 }\end{array}$ & 3.00 \\
\hline 9 & $\bar{M}$ & 47 & Bosniak III (MRI) & $\begin{array}{c}\text { pT1a, pNX } \\
\text { Clear cell RCC } \\
\text { G1 }\end{array}$ & 1.50 \\
\hline 10 & $\mathrm{M}$ & 51 & Bosniak III (CT) & $\begin{array}{c}\text { pT1a, pN0 } \\
\text { Papillary RCC } \\
\text { G1 }\end{array}$ & 1.50 \\
\hline 11 & F & 66 & Bosniak III (CT) & $\begin{array}{c}\text { pT1a, pN0 } \\
\text { Clear cell RCC } \\
\text { G1 }\end{array}$ & 3.00 \\
\hline 12 & $\bar{M}$ & 57 & Bosniak III (CT) & $\begin{array}{c}\text { pT1a, pNX } \\
\text { Clear cell RCC } \\
\text { G2 }\end{array}$ & 4.00 \\
\hline
\end{tabular}


True malignancy risk of Bosniak III cystic renal lesions

\begin{tabular}{|c|c|c|c|c|c|}
\hline 13 & $\mathrm{~F}$ & 68 & Bosniak III (CT) & $\begin{array}{c}\text { pT1a, pN0 } \\
\text { Clear cell RCC } \\
\text { G2 }\end{array}$ & 1.30 \\
\hline 14 & $\mathrm{~F}$ & 31 & Bosniak III (MRI) & $\begin{array}{c}\text { pT1a, pN0 } \\
\text { Clear cell RCC } \\
\text { G2 }\end{array}$ & 1.00 \\
\hline $15^{*}$ & $\bar{M}$ & 55 & Bosniak III (CT) & $\begin{array}{c}\text { pTX, pNX } \\
\text { Clear cell RCC } \\
\text { G1 }\end{array}$ & 12.00 \\
\hline 16 & $\mathrm{M}$ & 52 & Bosniak III (CT) & $\begin{array}{c}\text { No obvious tumour } \\
\text { mass } \\
\text { Cystic structure } \\
\text { Negative for RCC }\end{array}$ & 6.00 \\
\hline 17 & $\mathrm{~F}$ & 47 & Bosniak III (CT) & $\begin{array}{l}\text { Negative RCC (cystic } \\
\text { area) } \\
\text { Multi-loculated cystic } \\
\text { area with fibrotic wall } \\
<0.1 \mathrm{~cm} \text { ( } 4 \mathrm{~cm} \text { total } \\
\text { cystic area) }\end{array}$ & 4.00 \\
\hline 18 & $\mathrm{~F}$ & 53 & Bosniak III (CT) & Multicystic mass & 7.00 \\
\hline 19 & $\mathrm{~F}$ & 70 & Bosniak III (CT) & $\begin{array}{l}\text { Simple cortical cysts } \\
\text { with calcifications }\end{array}$ & 4.50 \\
\hline 20 & $\mathrm{M}$ & 75 & Bosniak III (MRI) & $\begin{array}{c}\text { Simple benign cortical } \\
\text { cyst }\end{array}$ & 4.00 \\
\hline 21 & M & 59 & Bosniak III (CT) & Hemorrhagic cyst & 2.50 \\
\hline 22 & $\mathrm{~F}$ & 54 & Bosniak III (CT) & Cystic structure & 3.00 \\
\hline 23 & $\mathrm{~F}$ & 56 & Bosniak III (MRI) & Cystic nephroma & 6.50 \\
\hline 24 & $\mathrm{~F}$ & 69 & $\begin{array}{l}\text { Bosnaik III (MRI) } \\
\text { Bosniak III (CT) }\end{array}$ & Cystic nephroma & 10.10 \\
\hline 25 & $\mathrm{~F}$ & 64 & Bosniak III (CT) & Complex renal cyst & 9.00 \\
\hline
\end{tabular}

CT: compouted tomography; F: female; M: male; MRI: magnetic resonance imaging; RCC: renal cell carcinoma. 